\section{Discussion}

There is extensive experience with the use of endovascular devices for closure of intracardiac defects and patent ductus arteriosus. However, there is little information on the use of these devices for intrapulmonary occlusions. The CardioSEAL double umbrella device (NMT Medical) was approved in the United States for closure of muscular ventricular septal defects in December 2001. Successful use of this device has been reported in occlusion of a large pulmonary arteriovenous malformation in an adult patient with hereditary hemorrhagic telangiectasia. ${ }^{1}$ In our patient this type of device was used to close an intrapulmonary vein. The procedure was successful; however, the patient returned 5 years later with hemoptysis secondary to erosion of the device into the right upper lobe bronchus. To our knowledge, this is the first reported case of such a complication. In a recent review of a group of 417 patients who underwent a device closure of secundum atrial septal defect, Chessa and associates $^{2}$ reported an $8.6 \%$ incidence of complications. The most common complication was a device malposition or embolization $(3.5 \%)$. Seven patients required surgical intervention after device embolization. No erosions were reported in this series; however, hemopericardium and fistula formation have been described after atrial septal defect closure. ${ }^{3,4}$ The mechanism of erosion is unknown, but it is likely that it is due at least in part to persistent pressure to the endovascular surface from a constrained device. In our case the arms of the CardioSEAL were partially collapsed in the vascular structure.

The use of stents, coils, and other intravascular devices has grown dramatically in the last several years. As their use increases, so does recognition of their limitations and the potential complications of migration and embolization. Intravascular foreign body migration is a well- documented phenomenon, particularly for intracardiac missiles and missile emboli. Previously, foreign body removal was advocated for most cases; however, a more selective approach has recently been advocated. ${ }^{5}$ The unstable nature of intravascular foreign bodies continues to be stressed.

The use of percutaneous interventional techniques for the treatment of congenital cardiac disease will continue to increase. However, the natural history of intravascular devices is not well known. Intravascular foreign objects have a tendency to erode into the surrounding structures and to migrate. As use of intravascular devices continues to expand, close follow-up of these patients is necessary.

\section{References}

1. Apostolopoulou SC, Kelekis NL, Papagiannis J, Hausdorf G, Rammos S. Transcatheter occlusion of a large pulmonary arteriovenous malformation with use of a Cardioseal device. J Vasc Interv Radiol. 2001;12:767-9.

2. Chessa M, Carminati M, Butera G, et al. Early and late complications associated with transcatheter occlusion of secundum atrial septal defect. J Am Coll Cardiol. 2002;39:1061-5.

3. Ewert P, Kretschmar O, Peters B, et al. Preliminary experience with a new $18 \mathrm{~mm}$ Amplatzer PFO occluder for small persistent foramen ovale. Catheter Cardiovasc Interv Aug. 2003;59:518-21.

4. Chun DS, Turrentine MW, Moustapha A, Hoyer MH. Development of aorta-to-right atrial fistula following closure of secundum atrial septal defect using the Amplatzer septal occluder. Catheter Cardiovasc Interv. 2003;58:246-51.

5. Symbas PN, Picone AL, Hatcher CR, Vlasis-Hale SE. Cardiac missiles. A review of the literature and personal experience. Ann Surg. 1990;211:639-48.

\title{
Tetralogy of Fallot and hypoplastic aortic arch: A novel perspective
}

\author{
David L. S. Morales, MD, Daniel J. DiBardino, MD, Wesley Vick, MD, Charles D. Fraser, Jr, MD, and \\ E. Dean McKenzie, MD, Houston, Tex
}

T etralogy of Fallot with coarctation of the aorta is a rare diagnosis that is counterintuitive to widely accepted theories of cardiac embryology. This arrangement of tetralogy of Fallot (TOF) with a left-sided obstructive lesion has only been reported in the literature in 9 previous patients. ${ }^{1,2} \mathrm{We}$ describe a unique variant of this unlikely association (TOF and a

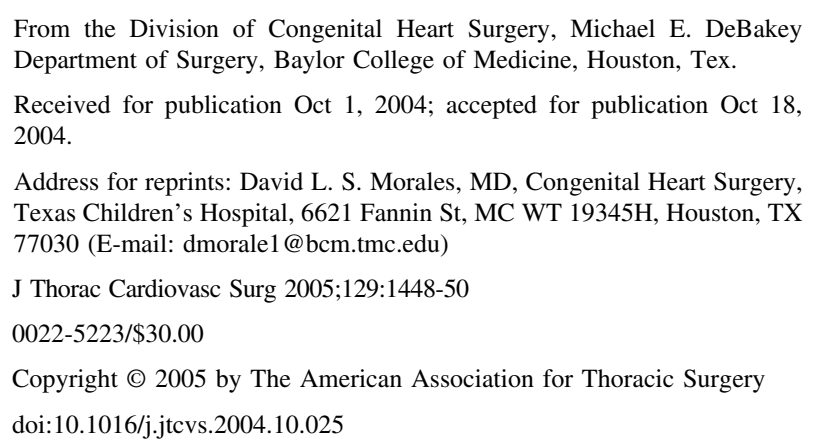

hypoplastic aortic arch) and discuss its possible embryology and morphogenesis.

\section{Clinical Summary}

A 4-month-old child, weighing $7 \mathrm{~kg}$, was diagnosed with TOF at birth. She was placed on beta-blocker therapy and monitored with oxygen saturations in the low 90s, despite severe right ventricular outflow tract (RVOT) obstruction (gradient of $64 \mathrm{~mm} \mathrm{Hg}$ ). Physical examination revealed the following blood pressures: right arm 83/40 $\mathrm{mm} \mathrm{Hg}$, left arm $89 / 39 \mathrm{~mm} \mathrm{Hg}$, and right leg $82 / 38 \mathrm{~mm} \mathrm{Hg}$, and a slight decrease in lower extremity pulses. A follow-up echocardiogram at 3 months revealed a large ascending aorta and a concern for aortic coarctation. Subsequent cardiac magnetic resonance imaging demonstrated TOF and a high right aortic arch with tubular hypoplasia and a small descending aorta with diastolic runoff (Figure 1). The narrowest segment $(0.25 \mathrm{~cm})$ was the distal arch between the right common carotid and right subclavian arteries.

At operation, there was an anterior malrotation of the dilated ascending aorta, a right aortic arch with mirror image branching, 

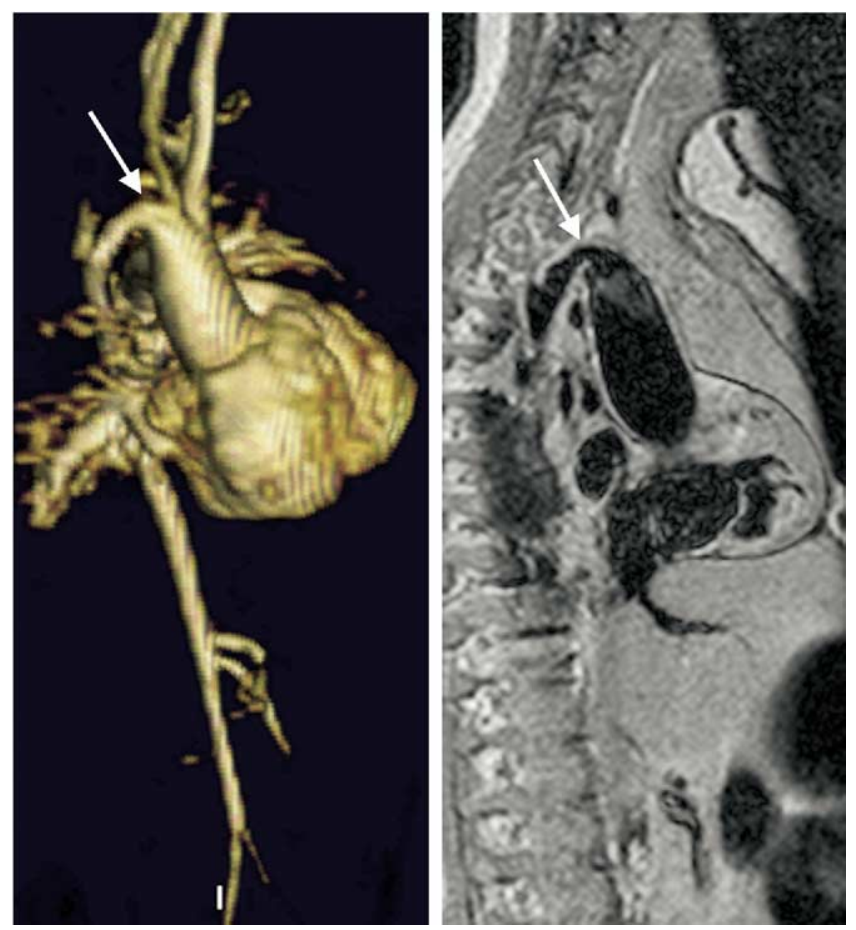

Figure 1. Coarctation of aorta. Left: Three-dimensional reconstruction of aorta from gadolinium contrast-enhanced magnetic resonance imaging demonstrates narrowing of superior aspect of aortic arch (arrow). Right: Spin echo image demonstrates obstructive ridge at superior aspect of aortic arch (arrow).

and a mildly hypoplastic descending aorta, measuring $7 \mathrm{~mm}$. The distal aortic arch was significantly elongated, and there was an acute angle of approximately $180^{\circ}$, "a buckling," within the distal aortic arch (Figure 2). We could not identify a ductus or ligamentum arteriosus. Intracardiac findings were consistent with TOF including severe infundibular obstruction.

The patient underwent transatrial repair of TOF, closure of the patent foramen ovale, and aortic arch advancement. The latter was accomplished by transection of the isthmus and an end-descending to side-ascending aortic anastomosis. Postoperative transesophageal echocardiography demonstrated good function, no residual shunt, and no RVOT obstruction. The patient recovered without incident and was discharged in 6 days, fully saturated and with no blood pressure gradient among the extremities.

\section{Discussion}

The development of a circulatory system with obstructed pulmonary and systemic blood flows seems counterintuitive and not compatible with fetal development. Yet 9 cases of this type have been reported, beginning in 1967, ${ }^{1}$ and these cases bring into question the long-held theories concerning the morphogenesis of aortic and left heart obstructive lesions. The well-known hemodynamic molding theory of Rudolph and associates ${ }^{3}$ states that aortic coarctation and arch hypoplasia develop because of a paucity of blood flow through the aorta during fetal development. This explanation does not suffice in a

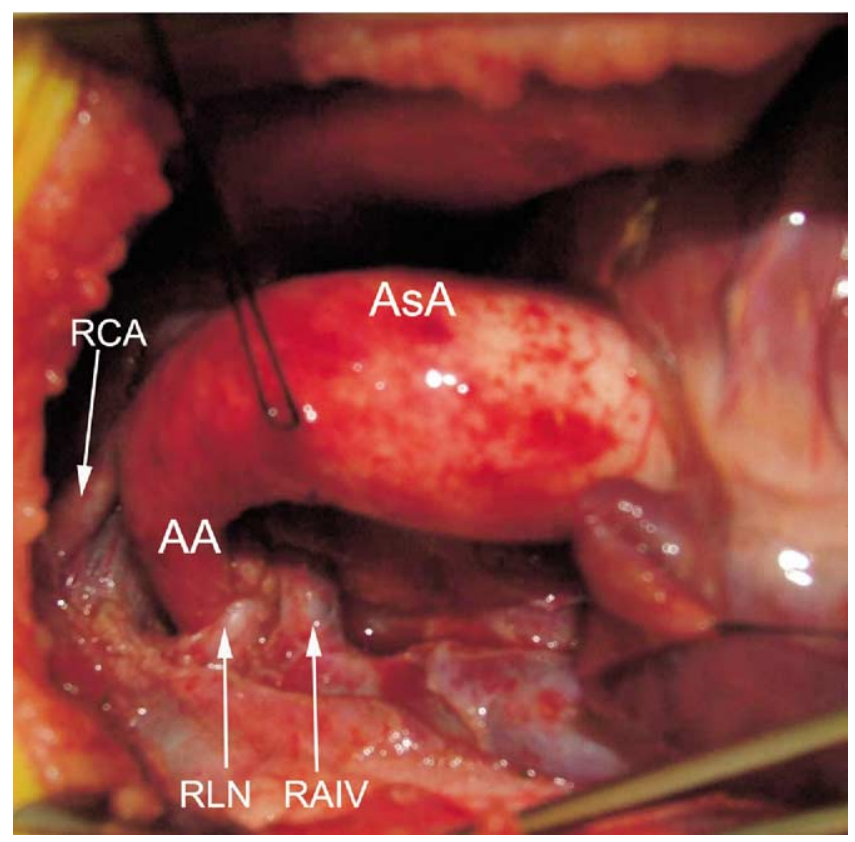

Figure 2. Intraoperative picture of hypoplastic arch. AsA, Ascending aorta; $A A$, aortic arch; $R L N$, recurrent laryngeal nerve; $R A I V$, retroaortic innominate vein; $R C A$, right carotid artery.

patient with TOF because right-sided obstructive lesions should result in increased right-to-left blood flow across the foramen ovale and through the left heart and aorta during fetal development, preventing aortic coarctation and hypoplasia. In addition, our patient had no left-sided obstructing lesions proximal to the aortic arch that could have interfered with arch development. One previously reported explanation is that infiltrating ductal tissue can cause aortic coarctation when it constricts postnatally. ${ }^{4}$ This seems implausible in our patient because there was true hypoplasia of the arch and no ductus or ligamentum was identified.

Right aortic arches predominate in the reported cases, as does abnormal brachiocephalic branching. These defects and TOF have been clearly associated with defects in cardiac neural crest cell migration. Neural crest cells are critical in the normal patterning of aortic arch vessels and aortic arch development during fetal life. Cardiac neural crest cell migration into the heart is a key factor in outflow tract septation, and abnormal migration can result in conotruncal septation defects. Interestingly, experimental ablation of embryonic neural crest cells produces a phenotype with 2 consistent components: (1) defective development in the RVOT leading to aortic override and/or ventricular septal defects; and (2) malformation and abnormal patterning of the aortic arch vessels leading to such defects as right aortic arches, retroesophageal subclavian arteries, and hypoplastic aortic arches. Genetic research in this area has used gene knockout models in mice and zebrafish to effect neural crest cell maturation and organization, which has resulted in aortic coarctation and RVOT abnormalities. $^{5}$

Previously accepted theories of diminished flow or ductal infiltration causing aortic coarctation make TOF and aortic arch hypoplasia an improbable combination. However, the current body of research on cardiac neural crest cells allows us to envision how these seemingly 
unrelated defects may be the result of a common mechanism: altered neural crest cell migration. Further embryonic and genetic experimentation will likely clarify the role of the neural crest cell at the various levels of cardiac development.

\section{References}

1. Nagao GI, Daoud GI, McAdams AJ, Schwarts DC, Kaplan S. Cardiovascular anomalies associated with tetralogy of Fallot. Am J Cardiol. 1967;20:206-15.
2. Elami A, Rein AJ, Preminger TJ, Milgalter E. Tetralogy of Fallot, absent pulmonary valve, partial anomalous pulmonary venous return and coarctation of the aorta. Int J Cardiol. 1996;52:203-6.

3. Rudolph AM, Heyman MA, Spitznas U. Haemodynamic considerations in the development of narrowing of the aorta. Am J Cardiol. 1972;30: $514-25$.

4. Skoda. Quoted by Hochhaus H. Ueber das Offenbleiben des Ductus Botalli. Deutsch Arch Klin Med.1893;51:1-10.

5. Houston MR, Kirby ML. Neural crest and cardiovascular development: a 20-year perspective. Birth Defects Res Part C Embryo Today. 2003;60(1):2-13

\title{
Novel management strategy for severe cyanosis after Sano modification of the Norwood procedure
}

\author{
Janet M. Simsic, MD, ${ }^{a}$ Angel Cuadrado, MD, ${ }^{\text {a }}$ Paul M. Kirshbom, MD, ${ }^{\text {b }}$ Kirk R. Kanter, MD, ${ }^{\text {b }}$ \\ Donna Ramaswamy, MPH, MS, ${ }^{a}$ Martha Clabby, MD, ${ }^{a}$ and Joseph M. Forbess, MD, ${ }^{\text {b* }}$ Atlanta, Ga
}

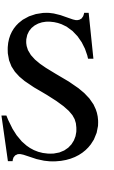

ano modification of the Norwood procedure has resulted in a more favorable distribution of systemic, pulmonary, and coronary blood flow. However, frequently these patients present with severe cyanosis caused by dynamic proximal shunt stenosis. The purpose of this review was to evaluate a management strategy for severe cyanosis in this patient population.

\section{Methods}

Between September 2003 and September 2004, 22 newborns underwent Sano modification at Children's Healthcare of Atlanta. One patient died before hospital discharge and was excluded from further analysis. Four (19\%) of the 21 remaining patients presented at $53 \pm 26$ days of age with oxygen saturations of less than $70 \%$. These 4 patients (group 1) were compared with the remaining 17 (group 2). Management strategy to treat cyanosis in group 1 patients consisted of increasing preload and $\beta$-blockade. Agematched hemodynamic data were evaluated between group 1 before therapy and group 2; variables before and after therapy in group 1 were also evaluated.

\footnotetext{
From Sibley Heart Center Cardiology/Children's Healthcare of Atlanta ${ }^{\mathrm{a}}$ and the Division of Pediatric Cardiothoracic Surgery, Emory University, ${ }^{b}$ Atlanta, Ga.

Received for publication Dec 7, 2004; accepted for publication Dec 15, 2004.

Address for reprints: Janet M. Simsic, MD, Sibley Heart Center Cardiology, 52 Executive Park South, Suite 5200, Atlanta, GA 30329 (E-mail: simsicj@kidsheart.com).

*Present address: University of Texas Southwestern Medical Center, Dallas, Tex.

J Thorac Cardiovasc Surg 2005;129:1450-1

$0022-5223 / \$ 30.00$

Copyright $\odot 2005$ by The American Association for Thoracic Surgery

doi:10.1016/j.jtcvs.2004.12.009
}

\section{Results}

Sano shunt size was $6 \mathrm{~mm}(\mathrm{n}=3$; birth weight, $>3 \mathrm{~kg})$ and $5 \mathrm{~mm}$ ( $\mathrm{n}=1$; birth weight, $<2 \mathrm{~kg}$; group 1) versus a shunt size of $6 \mathrm{~mm}$ ( $\mathrm{n}=13 ; 4$ patients with a birth weight $<3 \mathrm{~kg}$; 9 patients with a birth weight $>3 \mathrm{~kg})$ and $5 \mathrm{~mm}(\mathrm{n}=4$; birth weight, $<3 \mathrm{~kg}$; group 2). Hemodynamic variables before and after therapy in group 1 are shown in Table 1. In addition, comparison was made between hemodynamic variables at the time of presentation with cyanosis group 1 and group 2 at the same age (Table 2).

This management strategy prolonged the timing to bidirectional Glenn shunt by $70 \pm 40$ days in group 1 . A bidirectional Glenn shunt was performed at $123 \pm 32$ days in group 1 (4/4 patients) versus $133 \pm 28$ days in group $2(11 / 13$ patients, $P=.6)$.

\section{Discussion}

Secondary to the variable pulmonary and systemic vascular resistance ratio, the net effect of the Norwood procedure with a systemic-pulmonary artery shunt is runoff from the systemic to the pulmonary bed during diastole, resulting in a low diastolic blood pressure, a wider pulse pressure, and a change in the pattern of

TABLE 1. Hemodynamic variables before and after therapy in group 1

\begin{tabular}{lccc}
\hline & $\begin{array}{c}\text { Before } \\
\text { therapy }\end{array}$ & $\begin{array}{c}\text { After } \\
\text { therapy }\end{array}$ & $\boldsymbol{P}$ value \\
\hline No. of patients & 4 & 4 & 1.0 \\
Oxygen saturation (\%) & $62 \pm 9$ & $80 \pm 3$ & .01 \\
Heart rate (beats/min) & $151 \pm 13$ & $129 \pm 9$ & .03 \\
Respiratory rate (breaths/min) & $60 \pm 10$ & $50 \pm 22$ & .4 \\
Systolic blood pressure (mm Hg) & $90 \pm 1$ & $90 \pm 12$ & 1.0 \\
Diastolic blood pressure $(\mathrm{mm} \mathrm{Hg})$ & $44 \pm 8$ & $49 \pm 13$ & .5 \\
Mean blood pressure $(\mathrm{mm} \mathrm{Hg})$ & $60 \pm 5$ & $63 \pm 11$ & .5 \\
RVOT proximal gradient $(\mathrm{mm} \mathrm{Hg})$ & $92 \pm 12$ & $58 \pm 13$ & .02 \\
\hline
\end{tabular}

Mean $\pm \mathrm{SD}$; paired 2-tailed $t$ test. RVOT, Right ventricular outflow tract. 